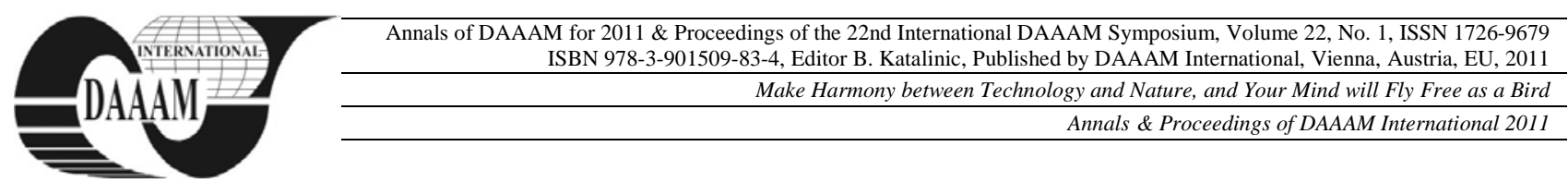

\title{
CURRENT TRENDS OF PRODUCTION COST ACCOUNTING
}

\author{
MICULESCU, M[arius] N[icolae]; LUT, D[ina] M[aria] \& MICULESCU, C[orina]
}

\begin{abstract}
The present economic context, in which firms operate, has significantly changed, the current environment being characterized by globalization, increasing competition, rapid changes, market segmentation, changes in technology, demand instability, importance of information. The economic environment influences organization in various forms, affecting strategy, structure, system control and performance. Consequently, these changes have determined deep mutations in the core of the Third Millennium society and they have also revolutionized both the means of production and a reshaping of management accounting and cost calculation. The latter represents the most important source of information in the decision taking process. In this context, it is highly relevant to analyse the present trend of adopting modern costing systems to the detriment of the traditional ones and to the adaptability of this reform in general practice.
\end{abstract}

Key words: cost, information system, management accounting, JIT method, ABC method

\section{INTRODUCTION}

Continuous market globalization and rapid technological changes in production have created worldwide fierce competition. In order to achieve various competitive advantages, the operational entities of a society must adopt strategies that integrate environmental opportunities, market and technology assets in the most efficient way. In this context, several issues, such as the modernization and transformation of management accounting, an adaptation to the reality and presents demands, to the modification of tools, processes and working methods in order to meet the present scientific and technical progress.

This situation raises the following question: have traditional costing systems become inefficient, remaining only a theoretical history in the evolution of management accounting and leaving the place to modern costing systems designed to meet current requirements adequately?

Many would unequivocally support the current trend but it is always recommendable to be aware that theory is the ideal and pure state of things while practice mirrors the real situation. Thus, we should have good knowledge of the past in order to approach the future with certainty.

\section{MANAGEMENT EVOLUTIONARY TRENDS}

ACCOUNTING

The American Institute of Certified Public Accountants (AICPA) states that management accounting manifests itself in practice in three areas:

- Strategic management - indicating the role of management accounting as a strategic tool of the organization;

- Performance management - developing the practice of business decision taking and managing the performance of the organization;

- Risk management - helping the development of the framework and practices for the identification, measurement, management and report of the risks that appear while achieving the company's objectives.

The accounting professionals' complementary studies and concerns supported by those from other related fields, such as marketing, management, etc., generated a revolution in the methodology of costing systems.

Management accounting should provide relevant information for decision taking or for the evaluation of stock items by the means of costs-related information. This may not be fully accomplished using traditional costing systems because the charging of indirect costs of calculation objects is made in a both rational and random manner.

Professor R.S. Kaplan says that traditional management accounting produces "wrong measures. It orientates the company in the wrong direction, rewards managers endangering the business and does not provide any improvement solution. The best thing we can do is to disable it, even to stop it! "(Lucey, 1992: 420)

In response to the technological changes, theorists and practitioners have started to develop new methods of costs calculation, such as:

- Just-in-Time method, which is both a method of manufacturing and cost accounting;

- Cost method based on activities (Activity Based Costing, $A B C$ ), which seeks, on one hand, to make a more accurate distribution of indirect costs in production costs, and on the other hand, it aims to establish a relationship between indirect costs and the activities they induce ;

- Costs - target method (target costing) aims to find a maximum allowable cost per product starting from a previous market prospecting before the designing of the product.

- Backflush Accounting method (BFA) uses a reverse approach of the production flow beginning with the value of sold goods compared to which costs will be distributed upon sold products and stock.

Accordingly to the JIT (Just-in-time) method, production is "pulled" downstream by customer orders, and it is not "pushed" upstream as in the case of scheduling based partially on sales forecasts which are adjusted by the stock of final products. At this stage, the inherent risk (presented generally by the traditional methods) of the excessive growth of stocks with serious financial consequences disappears, especially if the final products and components are not standardized. The JIT system, excellently suited for repetitive manufacturing, organizes manufacturing not after a schedule but according to the orders received from customers, which allows:

- the improving of trade effectiveness;

- stocks reducing (target: Stock zero), job, materials and raw materials losses and, consequently, reduction of production and storage costs, creating an increase in profit margins;

- reduction of the working capital need, thus the increasing of the capital return.

JIT enables the increasing of system responsiveness to the demanded commercial production. Thus, the company seeks to 
improve the production system response by allowing a much faster response to changes of the quantitative and qualitative demand. System stagnation must be diminished by redesigning the production cycles in order to obtain a better responsiveness. The traditional organizational forms often have periods of weeks or even months. In other words, this means that the system does not respond to a change of the demand until after this period. The reducing of the cycles is expressed by a reduction of the stocks at all levels, stocks of raw materials being included, which means that suppliers deliver on a rhythmic basis. There will be a reduction in stocks of production in progress and a reduction in the time of passage through all the workshops. These changes will ultimately lead to reduced stocks of final products, meaning increased production mobility.

"Stocks reduction is a subordinate goal of the reducing cycles. There is a linear relationship between cycles and average inventory levels. The determination of the variation of a factor is actually reduced to the finding of another factor's variation, in the same direction and in the same proportion. However, it is often easier to express objectives in terms of reducing stocks because they are more visible and more easily controllable than periods of time. If you want to reduce stocks, you must eliminate the factors (elements) that led to their increase, such as quality flaws, equipment failures, setting times, etc. The improvement of the performance at each of these levels does not represent a sole objective but rather a necessary condition to reduce both inventories and cycles. “

Activity Based Costing highlights the causal link between resources, activities and the calculation subject according to the principle "activities consume resources and products consume activities." This approach involves the abandoning of vertical steering of the enterprise, with riding crop down on functions and adopting a transversal approach, considering the value chain, a concept developed by Michael Porter. Cost activities (process) do not only meet the last objective pursued in the classification of costs but they can equally serve stock assessment, and decision making. The ABC system is a complex one, "promising" a "cleaner" and a more "useful" cost for managers. Thus, the question "Is ABC the solution?” springs up.

Activity based costing helps managers calculate a completely relevant cost. The implementing of such a system is very expensive though and it should be taken into consideration that the information provided must be really used for decision making and profitability improvement. Otherwise, the ABC method will involve high costs for its implementation.

The basic concept of the ABC method is that products do not consume resources but activities, and activities consume resources - hence the object of calculation must be the work and not the product.

Although it is a complete system that calculates a cost, it differs from the traditional methods. The most important differences are following:

- both production costs and general and administration costs can make up the cost of product distribution, following a logic of cause-effect type;

- some production costs may be excluded from the cost of the product;

- more work units are used for the distribution of indirect costs.

The ABC method is motivated by the belief that traditional accounting information is useful to managers who are interested in assessing the effectiveness of resource allocation decisions in their businesses. This traditional information is involved in meeting the needs of the external auditors or other persons who are interested in financial and accounting records.

In traditional systems, when establishing the product's cost, only the production costs are taken into consideration, while distribution costs and general administration costs are associated with the period cost and are not allocated to products. However, some of these costs, that apparently are unrelated to the products, can be easily identified on products (transport costs for a sale).
Even more, within traditional systems, all production costs (direct and indirect) are allocated to products. But there are some indirect costs that are charged to products even though they have nothing to do with their production (e.g. salary of the person repairing equipment). These costs are considered a part of the period cost in the activity calculation compared to traditional calculations.

Therefore, the context of the emergence and the necessity of the ABC method can be explained by the following elements:

- the increasing of indirect costs in most sectors of the economy, both in absolute and relative value;

- the changing nature of indirect costs. The share of indirect costs in total costs increased at the expense of variable costs related to production volume, this being due to the complexity, diversity of product range and product quality;

- the evolution of direct labour. The proportion of direct labour cost in total cost was reduced steadily.

Target Costing is part of a wider approach, aiming to analyse cost bearer throughout its lifetime, especially in the design phase. The target cost is a market-oriented approach and is applied from the design phase (design) of the product. Product design takes a long time because it follows from the elimination phase of any subsequent changes, whose implementation is more expensive. Target cost is determined by deducting a profit margin that the firm wishes to achieve from the selling price of a product or a service. Target costing is not just a means of controlling costs, but also a profit planning approach (results) and cost management.

\section{CONCLUSION}

Under globalization, and thus under the increase of competition, companies have a growing need to find solutions as quickly and as efficiently as possible in order to survive in the new global market. Management accounting and costing are part of the tools that can support managers' actions in this regard, but their value is null if the role and the benefits it could bring are not understood. The famous Michael E. Porter highlights the importance of cost knowledge for the company's management, and that higher quality means lower cost. Thus, Porter said a few years ago that "for a company to be competitive in the long run, it must provide customers with greater value or a value comparable to a lower cost, or both." (M.E. Porter, 1996:62)

From the extensive theoretical review we may agree on the advantages of modern costing systems, promoting the idea of transforming the traditional systems into a page of history in the research specialized literature. Although the sense of abandonment is unanimously supported, within this context, however, it is necessary to keep a note of wisdom, because there is a risk that 'any economic advantage could be ephemeral and any bet on the future could be extremely risky.' (Tabără \& Mihail, 2004).

\section{REFERENCES}

Lucey, T. (1992) Management Accounting, 3rd Edition, D.P. Publications, London

Porter, M.E. (1996) What Is Strategy ?, Harvard Business Review, November/ December

Tabără, N., Mihail, C. (2006) Management control in the new competitive environment, Journal: Accounting, auditing and business expertise No. 2,February, p. 5., Bucharest.

Watson, T.J. (2001) In search of management, Reissued Edition, International Thomson Business Press, London 